\title{
A TRANSANIMALIDADE DO HOMEM: UMA PREMISSA DO PRINCÍPIO RESPONSABILIDADE
}

\author{
Jelson Roberto de Oliveira \\ PUC-PR
}

\begin{abstract}
We intended in this article to show how the concept of human transanimality serves as a guiding principle that provides clues to think the assumptions of responsibility principle formulated by Hans Jonas. For this, we will examine the notion of natural liberty and its dangers with regard to non-being as well as the notion of dialectic freedom of the human condition as part of the uniqueness of animal existence. We will see that in the human case, the evolution of life has reached its apex, which is verified for its transanimal existence revealed by the ideas of technique, art and metaphysics. We finely got the notion that in the human, as transanimal, that freedom reaches its peak and therefore it is effective demand of responsability.
\end{abstract}

Keywords: Man, transanimality, freedom, responsibility.

Resumo: Pretende-se, nesse artigo, mostrar como o conceito de transanimalidade do ser humano serve de fio condutor que fornece pistas para pensar as premissas do princípio responsabilidade formulado por Hans Jonas. Para tanto, analisar-se-á a noção de liberdade natural e seus perigos no que diz respeito ao não-ser, bem como a noção de liberdade dialética da condição humana como parte da singularidade da existência animal. Constatarse-á que, no caso humano, a evolução da vida atingiu seu ápice, o que se verifica por sua existência transanimal revelada pelas ideias de técnica, arte e metafísica. Chega-se, assim, à noção de que é no humano como transanimal que a liberdade alcança seu auge e, consequentemente, nele se efetiva a demanda da responsabilidade.

Palavras-chave: Homem, transanimal, liberdade, responsabilidade. 


\section{Introdução}

A ética da responsabilidade, de Hans Jonas, está baseada numa tentativa de recolocar o problema da relação entre humano e extra-humano (ou entre homem e natureza, espírito e natureza ou entre natureza e civilização) sobre novos patamares, distantes daqueles marcados pelo mote dualista de tipo cartesiano que reinou com severidade ilimitada na filosofia moderna: não há dúvida de que, ao enfrentar essa problemática, Jonas se defronta com um dos emblemas da modernidade, não só no que tange a Descartes, mas também a Kant, por cujas mãos o dualismo foi transformado em uma ética.

Pretendemos mostrar como a proposta de um princípio responsabilidade que dê conta do novo cenário tecnológico parte de uma inovada forma de conceber a relação entre necessidade e liberdade no que tange à compreensão do fenômeno da vida. Se a tradição moderna ligou a primeira à natureza e a segunda apenas ao reino da racionalidade, Jonas, como resultado de suas pesquisas em torno de uma filosofia da biologia, chega à afirmação de que a liberdade é uma característica presente em todo o mundo orgânico e não apenas no humano.

Trata-se de esboçar uma tentativa de superação ontológica do dualismo reinante na filosofia ocidental moderna e por cujo intento, conforme pretendemos demonstrar aqui, chega-se também à superação ética desse dualismo. Essa intenção aparece, por exemplo, em Evolution und Freheit, de 1983-1984, na qual o autor mostra como, a partir do olhar exclusivo que a tradição ocidental dirigiu às características humanas, é possível vislumbrar vários erros de avaliação, dos quais o principal provavelmente seja o fato de que, assim distinto, o homem esqueceu que o resultado seria a privação dessas características dos demais seres, fazendo com que as ciências da vida ignorassem, por exemplo, as dimensões interiores e espirituais da vida, fechando os olhos às características que, por estarem no homem, só podem ter derivado das demais formas de existência orgânica ( $c f$. JONAS, 2005, p. 25). Essa é a forma pela qual se pode compreender o intento de Jonas de fundar a sua ética da responsabilidade numa metafísica da natureza que está ligada a uma filosofia da vida em geral ou do organismo em particular. 
Nesse sentido, o homem seria apenas um resultado do progresso que liga o "primitivo" ao "evoluído", vindo a representar, pela consciência e pela busca da verdade, o degrau mais elevado desse desenvolvimento. Para Jonas, o homem não é mais um ente desligado das demais formas de vida e do reino orgânico em geral, mas apenas uma forma mais acabada do desenvolvimento vital, no qual a liberdade atinge um grau superior apenas na medida em que tenha emergido já nas suas formas mais primitivas. Esse, aliás, aparece como o grande objetivo de sua filosofia da vida: "Esse tema, comum a toda a vida, buscaremos acompanhá-lo através do crescente desenvolvimento das capacidades e funções orgânicas: metabolismo, movimento e apetite, sensação e percepção, imaginação, arte e conceito - uma escala ascendente de liberdade e risco que culmina no ser humano (...)" (JONAS, 2004, p. 8). Assim, a racionalidade do ser humano, como veremos, é expressão de sua plena liberdade e de seu maior risco - porque, no limite, a liberdade emerge como tentativa e desejo de desligamento da vida em relação à matéria inerte e, consequentemente, quanto mais desligada, mais a vida se torna suscetível aos perigos de sua própria extinção. Como tal, no caso humano, essa liberdade exige o exercício da responsabilidade, dado o poder imenso que o ser humano, pela via da técnica amparada pela compreensão materialista da vida, adquiriu nos últimos anos. O homem é parte de um desenvolvimento progressivo que tem nele o seu auge e é nele, portanto, pelos maiores riscos aí vislumbrados, que se torna também visível a maior responsabilidade.

As duas formas de manifestação desse desenvolvimento são identificadas por Jonas pela medida de "saber" e de "poder" presentes nos organismos em geral. Quanto ao primeiro, trata-se de identificar a "amplitude e a precisão da experiência" (JONAS, 1998, p. 161') que levam desde a capacidade sensorial à "objetivação mais complexa e livre" que é representada pela consciência racional. Quanto ao segundo, trata-se de analisar o progresso pelo tamanho e pelo tipo de intervenção que o organismo provoca sobre o mundo e que é resumida pelo autor sob o conceito de "liberdade de ação" cuja manifestação se daria nas funções orgânicas da percepção e da mobilidade.

\footnotetext{
${ }^{1}$ A tradução das citações da obra Philosophishe Untersuchungen und metaphysische Vermutungen foi feita por nós a partir do texto em espanhol, em comparação com a versão alemã de 1992 (Insel Verlag, Francfort del Meno und Leipzig)
} 


\section{A liberdade natural e o risco do não-ser}

Para Jonas, a liberdade é uma característica do próprio metabolismo e não estaria reduzida ao âmbito da racionalidade (como em Kant, por exemplo). Mesmo no âmbito da inevitabilidade que marca a presença do orgânico no mundo físico, haveria um acento de liberdade, como "uma maneira de existir que é própria ao organismo em si mesmo e que, portanto, é partilhada por todos os membros - mas por nenhum não-membro - da classe de 'organismos"' (JONAS, 1998, p. 17). A liberdade, então, como conceito ontológico, marca a existência orgânica desde o modo mais inferior, desde as quais as formas superiores evoluíram.

A primeira manifestação desse princípio ontológico é descrita por Jonas como a "irrupção do ser no espaço ilimitado das possibilidades" (JONAS, 1998, p. 17), ou seja, como liberdade do ser em sua saída do não-ser, o desprendimento do vivente da matéria física geral, ou seja, a separação da vida da totalidade da natureza que, em sua maioria, está, como propõe o autor, marcada pela regra da morte que nada mais seria do que o resultado do limite mesmo do conhecimento: "o conceito de conhecimento determina o conceito de natureza" (JONAS, 2004, p. 20). Para Jonas, "o inerte passou a ser o conhecível por excelência” (JONAS, 2004, p. 20) e isso não passaria de uma limitação imposta à capacidade do conhecimento. A partir do livre desenlace primitivo do ser em relação ao não-ser, tornou-se possível pensar a liberdade no âmbito subjetivo. É por isso que Jonas afirma que a liberdade "pode servir de fio condutor para a interpretação do que chamamos 'vida", (JONAS, 1998, p. 17).

Essa saída do vivente do reino geral do não-vivente se deu, entretanto, como um gesto de perigo, vindo a instalar o paradoxo ser e não-ser. O lance perigoso da vida está no fato de que essa separação se deu sem romper aquilo que Jonas chama de "dependência precária" do vivente em relação ao nãovivente, ou seja, do organismo em relação à natureza inorgânica. Nessa perspectiva de dependência, o organismo vivo passou a possuir seu ser de maneira "condicional e revogável" (JONAS, 1998, p. 18). A marca do metabolismo seria, então, a um tempo, sua "capacidade e sua necessidade", fazendo com que o ser dependesse inteiramente do não-ser, ou seja, o ser se instala na existência a partir de uma relação compulsória com o não-ser de onde ele mesmo adveio como ser. O ser está, assim, intimamente ameaçado 
pela sua própria negação. O ser não é, pois, algo dado de forma definitiva, mas ameaçado pela compulsoriedade da relação com seu não-ser e pela necessidade de sua própria afirmação: "o ser se converteu em uma possibilidade constantemente proposta, que deve se contrapor ao seu contrário sempre presente, o não-ser, pelo qual, no final, contudo, será inevitavelmente devorado" (JONAS, 1998, p. 18). É sobre essa polaridade que a vida se apresenta, portanto, como eterna possibilidade.

Mesmo tendo certeza de que sua finalidade inelutável é o não-ser, o ser precisa, para se firmar na existência, impor-se como ser a partir justamente do não-ser, por um esforço extremo, já que o não-ser conta com a generalidade quando se vislumbra o reino inorgânico em geral - a regra é a morte. Note-se que o resultado desse argumento conduz Hans Jonas à temática da finitude do ser, ou da mortalidade do vivente, na medida em que ela passa a ser compreendida como parte essencial de todo vivente pela via de uma dependência necessária. "A vida não é mortal apesar de ser vida, mas pelo fato de sê-lo, por sua constituição originária” (JONAS, 1998, p. 19).

Em um texto de 1991, essa temática da morte é resgatada por Jonas como princípio constituinte do ser humano a tal ponto que o adjetivo "mortal” passou, desde Homero, a caracterizar o próprio ser humano. Mas essa não é uma característica apenas dos seres humanos, mas de todos os organismos vivos, já que com eles "compartilhamos a sina da mortalidade com as demais criaturas, de que toda a vida é mortal, e de que a morte é, inclusive, a contrapartida da vida” (JONAS, 2009, p. 265). A morte é tratada pelo autor como um "atributo essencial da vida" (JONAS, 2009, p. 265) e não apenas como uma definição que conduz à possibilidade (o vivo pode morrer), mas à necessidade (o vivo deve morrer) e, disso, o autor retira a paradoxal afirmação: "À possibilidade ininterrupta associo o fardo da mortalidade, e à necessidade última associo a benção da mortalidade" (JONAS, 2009, p. 266). Entre as causas da possibilidade de que um ser vivo venha a morrer está um outro ser vivo. Trata-se de um "modo de ser" pelo qual o vivo se constitui como vivo. Essa constituição do ser se dá como um fazer, segundo Jonas, já que é pelo que faz que um organismo, por sua constituição ontológica, se estabelece enquanto tal. Mas como esse fazer depende estritamente do ambiente, o ser vive intensamente o risco do não- 
fazer e, consequentemente, do não-ser. O metabolismo (Stoffwechsel2) não é nada senão o resultado dessa relação entre ser e fazer: segundo Jonas, isto significa "existir por meio da troca de matéria com o ambiente, incorporá-lo de modo transitório, usá-lo, e excretá-lo mais uma vez” (JONAS, 2009, p. 267). O ser é marcado, primeiramente, pela constância da matéria desde os seus primórdios, pela via de uma reafirmação em cada momento de sua permanência no tempo. Mas essa afirmação não vale para os organismos vivos, já que, em termos materiais, ele nunca permanece o mesmo desde seu aparecimento. A sua característica é, justamente, a transitoriedade material e, malgrado isso, ele continua sempre o mesmo em sua identidade. Aliás, caso permanecesse o mesmo, o que é vivo deveria ser definido como um cadáver como um que é morto. Por isso afirma Jonas: "assim, nos deparamos com o fato ontológico de uma identidade totalmente diferente da inerte identidade física, não obstante fundada nas transações entre as informações dessa identidade simples do inorgânico" (JONAS, 2009, p. 268).

Entretanto, o sistema vivo não é comparável a uma máquina em seus processos de fluxo (energia) e refluxo (resíduo), porque diferente daquilo que ocorre no sistema mecânico, o "sistema metabolizante" se faz a si mesmo em seu fazer, ou, nas palavras de Jonas: "o sistema mesmo é, em sua totalidade e continuamente, o resultado de sua atividade metabólica e, ademais, que nenhuma parte desse 'resultado' deixa de ser objeto do metabolismo, ao tempo que é seu executor” (1998, p. 23). No caso do vivo, o metabolismo, por isso mesmo, não é apenas uma função, mas a sua própria constituição, pois ele garante determinada unidade que é ao mesmo tempo sua existência, sua duração e sua permanência (ou "mesmidade") na duração. Só assim se poderia, segundo Jonas, entender um indivíduo ou mesmo um sujeito, ou seja, como uma autointegração da vida, uma unidade autounificadora em constante renovação de si mesma: "a totalidade é aqui a execução ativa da

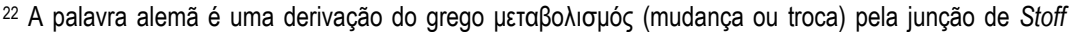
(matéria) e Wechsel (troca), remetendo, portanto, à "troca de matéria" dos organismos e pelas quais cada organismo processa e transforma as substâncias químicas angariadas pelo meio. Jonas usa 0 termo no sentido químico, explicitando a ideia de uma mudança nas moléculas de um corpo em função do seu entorno (p. ex.: JONAS, 1998, p. 22, onde o autor tematiza o conteúdo transitório da matéria que forma cada organismo, fazendo com que cada um seja sempre materialmente diferente de si mesmo, a não se pelo processo da morte, que é quando esse processo cessa) através do conjunto de trocas de energia efetivadas por um organismo em suas funções primordiais, expressas pela respiração e pela pulsação cardíaca, por exemplo.
} 
autointegração; a forma não é o resultado, senão a causa da montagem material do que se constitui sucessivamente. A unidade é aqui autounificadora por meio da multiplicidade mutável. A mesmidade é a constante autorrenovação por meio de um processo sustentado pelo fluxo do sempre diferente" (JONAS, 1998, p. 25). O vivo é ao mesmo tempo dependente da substância material da qual é feito e ao mesmo tempo sua identidade não coincide com ela, fazendo com que toda forma orgânica mantenha aquilo que Jonas chama de "liberdade precária" com a matéria. A "liberdade básica" do organismo, ao contrário, estaria amparada numa “independência da forma em relação à sua própria matéria” (JONAS, 1998, p. 26) e a medida desse distanciamento ajuda a calcular o grau da revolução ontológica que distancia os viventes dos não-viventes, e deles consigo mesmos: o primeiro passo da revolução ocorreu por meio do metabolismo, pelo qual a forma teria se emancipado da matéria, que não é outra coisa do que uma libertação da fixidez representada pela identidade da matéria consigo mesma, expressada por Jonas como um "vazio e lógico $A=A$ ", na qual toda a sua duração está ligada à permanência de seu estado e estágio e esta é toda a sua sucessão, sem reafirmação mas apenas com uma oca trajetória de continuidade. A permanência no espaço-tempo de seu proprium é seu único critério de identidade no qual não há ameaça e, por isso, não há aí nenhuma espécie de interioridade.

\section{A liberdade dialética da condição orgânica: o encontro do ser consigo e com o outro}

No caso do orgânico ocorre algo absolutamente diferente. Pela sua precariedade e instabilidade, bem como pelo processo metabolizante que lhe é próprio, dele se ausenta qualquer substrato persistente em referência a alguma possível exterioridade. Por isso, a identidade do vivo é uma "identidade interior" que está "implicada na aventura da forma e se induz espontaneamente de seu testemunho morfológico exterior, que é o único acessível à observação" (JONAS, 1998, p. 27). Essa observação, afirma Jonas, só pode ser feita por quem, na observação do fenômeno da vida, se dê conta de que é/tem um corpo: "estamos preparados [para essa experiência] em virtude do que somos". Com esse movimento, a vida é compreendida a partir de um "si-mesmo" que ao mesmo tempo remete à identidade interior de cada vivente e ao seu isolamento em relação aos demais: "a mesmidade do 
organismo se define como individuação radical e heterogeneidade em meio a um universo de entes homogêneos e conexos entre eles" (JONAS, 1998, p. 28). No caso do vivente - ao contrário do inorgânico - a identidade só é possível através da alteridade, cuja implicação é uma constante reafirmação, uma inevitável tensão perante as forças igualadoras que representam o seu perigo supremo. Tudo o que não é o vivente passa a ser a sua ameaça: mas, paradoxalmente, o mundo que é o outro é também o mundo que é ele, pelo qual e contra o qual ele se torna o que é, se efetiva, se conserva, se amplia. "Sem essa oposição universal da outridade não poderia emergir nenhuma mesmidade” (JONAS, 1998, p. 28). É dessa tensão que Jonas faz surgir a noção de liberdade que é, no caso orgânico, de natureza dialética, já que, no metabolismo, ela se manifesta numa confusão entre um "poder" e um "dever": "Seu 'pode' é seu 'deve', posto que sua efetuação é idêntica a seu ser" (JONAS, 1998, p. 28).

Reside aqui o difícil caminho que Jonas faz ao retirar o princípio ético de um princípio ontológico: no caso da vida, o seu ser é seu deve-ser e esse é seu gesto de liberdade plena - e não apenas de necessidade. Como liberdade, o metabolismo é, para a vida, uma "imposição vinculante" porque ele se faz por ela: fazendo o que pode fazer, o vivente não pode deixar de fazer o que pode, ou seja, como capacidade de fazer-se, ele não pode não usufruí-la a não ser deixando de ser. Trata-se, então, no caso do vivente em geral, de uma liberdade ainda precária porque é uma "liberdade de fazer, mas não de deixar de fazer”. Liberdade e necessidade, no caso do organismo vivo, relevam-se pela via do metabolismo, como a raiz mais original da vida que se torna, assim, dialeticamente, uma crise constante, uma marcante insegurança frente ao não-ser, uma fragilidade inerente, sendo no fim apenas "a perpetuação de uma crise” (JONAS, 1998, p. 19).

É esse eterno paradoxo que, segundo Jonas, se apresenta no caso humano como pergunta pelo sentido da existência, como formulação que tenta dar forma àquilo que permanece obscuro, e que se expressa na forma da linguagem que se efetiva humanamente. Jonas está consciente do antropomorfismo que nasce dessa reivindicação teórica o qual coloca o homem como doador de sentidos através da linguagem. Entretanto, adverte o autor, não se trata de um antropomorfismo que se ergue sobre uma pretensa superioridade da razão como isolamento das demais condições e formas da vida, mas do "caráter paradigmático de sua [ser humano] integridade 
psicofísica” (JONAS, 1998, p. 20), que se caracteriza como o ápice do desenvolvimento da totalidade ontológica.

Essa posição do humano teria, segundo o autor, sido questionada pela teoria darwinista da evolução ${ }^{3}$, pois aí se destruiu a "posição especial do ser humano" pela idéia de uma "continuidade da descendência" que tornou impossível pensar o espírito humano como um acontecimento repentino na história da vida. Ao contrário, o resultado final do evolucionismo seria paradoxal, já que ele "socavou o edifício de Descartes" ao mostrar que o espírito é contínuo em relação ao desenvolvimento mais básico dos organismos e, assim, seria "injustificável negar graus proporcionais de espírito às formas antepassadas mais próximas ou distantes e com ele a qualquer escala da animalidade" (JONAS, 1998, p. 21). Ou seja, em termos de conseqüência, o evolucionismo representaria um avanço teórico em relação ao monismo materialista moderno: "se o ser humano é parente dos animais, então os animais também são parentes dos seres humanos” e assim, partilhariam com ele alguma dose de espiritualidade, baseada no princípio de liberdade presente em todo ser vivo desde suas formas mais primitivas. A nota 13 do capítulo Gnose, existencialismo e niilismo, d'O princípio vida (JONAS, 2004, p. 247) parece evidenciar essa compreensão: “'Animal' no sentido grego $(=\zeta \omega o v)$, não significa animal $=$ bestia, mas sim todo 'ser animado' (= vivo), excluídas as plantas mas incluídos os demônios, deuses, astros animados, ou mesmo o universo animado como o maior e o mais perfeito ser vivo". Assim, como animal, o homem seria apenas um avanço a mais na história processual da vida, já que o reino da alma foi estendido desde o ser humano para todo o domínio do vivente. (JONAS, 1998, p. 21). Assim, a interioridade seria co-extensiva com a própria vida: onde há vida, há interioridade e, consequentemente, não bastaria mais apenas uma teoria mecanicista de compreensão da vida - já que esse tipo de teoria deixa-se pautar apenas pelos conceitos da exterioridade (aos moldes da res extensa cartesiana).

\footnotetext{
3 Segundo relato de sua esposa no prefácio de suas Memórias (2005, p. 10), em 1945, enquanto lutava na II Guerra Mundial, Jonas teria se interessado pelas ciências naturais e ela the teria enviado para o campo de batalha livros de Charles Darwin (além de Aldous Huxley e John Haldane). Dessas leituras teriam surgido as chamadas "cartas formativas", que deram origem mais tarde à obra Organismo e Liberdade, em boa parte posteriormente intitulada, O princípio vida, publicado em 1966, após ampliação de fontes de leitura, entre as quais se destacam as obras de Alfred N. Whitehead.
} 
Isso significa dizer que todo vivente encontra no mundo exterior a si mesmo as condições para que a vida ocorra e aí ele necessita dispor desse conteúdo material a seu favor. A vida se orienta em direção ao mundo pela via de uma interdependência e sua condição é de uma abertura para o encontro com a realidade exterior que lhe fornece as condições de existência. O encontro é o outro nome da dialética e se efetiva como o momento da liberdade. A vida cria, por isso, continuamente encontros com o mundo exterior e possibilita, pela necessidade desse encontro, a experiência que é, no limite, uma experiência de ter em si algo que lhe é estranho porque pertencente ao mundo. Afirma Jonas: “o 'mundo' está presente desde o primeiro começo como um horizonte ao qual abre a mera transcendência da carência e que amplia a particularização da identidade interior convertendo-a num entorno envolvente de relação vital” (JONAS, 1998, p. 29). Por essa via, no caso do vivente, o ter-um-mundo constitui a possibilidade de sua transcendência como necessidade orgânica fundamental, ou seja, só perante o mundo que ele tem/adquire é que o vivente experimenta a vida. Esse é o seu gesto de liberdade frente à matéria da qual ele faz emergir a sua forma, cuja efetivação se dá pela capacidade de relacionamento com o mundo - por esse relacionamento a "liberdade se apodera de sua própria necessidade".

O tipo de relacionamento ou de encontro é descrito por Hans Jonas como uma demonstração de interioridade ou mesmo de subjetividade, seja porque ela evoca um tipo de sentimento, de sensibilidade ou mera resposta a um estímulo ou aspiração. Qualquer que seja a "motivação" relacional, o organismo expressa uma "atenção" dirigida a sua existência ou continuidade no existir, superando o abismo inicial que o separa do mundo exterior. A relação é uma forma de ponte que religa o organismo ao mundo como seu entorno físico. É pela via da afetação desse mundo exterior que o próprio organismo se efetiva enquanto tal e se singulariza: "com o primeiro traço de um estímulo subjetivo, com a vivência mais rudimentar do contato se abre uma fenda na clausura do ser" (JONAS, 1998, p. 30). Essa abertura, provocada pelo encontro do ser com o outro, o estimula na sua própria mesmidade e singularidade, pela via do contraste. É ele que garante a dimensão de uma interioridade, portanto fazendo com que, além da necessidade orgânica da transcendência (de dentro para fora), o ser tenha também uma influência da receptividade do mundo exterior (de fora para dentro) que também o singulariza. Esse processo influenciaria, segundo Jonas, a própria vida, informando-a e dando condições para que ela seja 
seletiva e não apenas cega. Está posta, dessa maneira, a possibilidade de se pensar a comunicação entre todas as coisas, algo que soa também como denúncia dos limites da análise mecanicista.

Jonas sugere ainda outra dimensão de compreensão da transcendência, não apenas uma que esteja ligada ao espaço, mas também ao tempo e pelo qual se pode pensar no futuro da vida, na sua visada ao depois, via pela qual é possível articular a satisfação ou a frustração das necessidades vitais como forma de vista ao futuro. É do presente e ainda mais, do passado, que depende o futuro da vida e, por outro lado, é da realização imediata de suas intenções que ela projeta o seu futuro, ao tempo que esse futuro também se realiza pela efetivação da premissa do presente - é o presente que anima o futuro, portanto, e executa a transcendência da vida.

\section{A singularidade da existência animal}

A pergunta inicial e talvez a mais problemática dessa tese jonasiana poderia ser formulada agora: em que tipo de forma orgânica está pensando o autor ao formular suas concepções? Jonas afirma que em todas as formas de vida orgânica, mas obviamente sua visão não é ingênua: segundo ele, é na existência animal que essas características se realizam plenamente, já que só no animal existe liberdade de movimento, percepção e sentimento - três características, aliás, que distinguem o animal do vegetal. Pela via da percepção e do movimento a liberdade se realiza como aprimoramento dos primeiros gestos metabólicos e efetiva o aperfeiçoamento das faculdades orgânicas no caminho evolutivo da vida que é caracterizado, como vimos até aqui, por dois modos: uma abertura para o mundo e uma crescente individuação (JONAS, 1998, p. 32). Se no caso geral da vida esses dois processos são provocados pela mera excitabilidade ou reação a estímulos, no caso dos animais, a existência de estruturas motoras e de um sistema nervoso central, além do desenvolvimento dos sentidos, possibilita aquilo que o autor chama de "verdadeira relação com o mundo" (JONAS, 1998, p. 32). É a capacidade de integrar os múltiplos dados do mundo que possibilita pensar no espaço não mais como dimensão de necessidade, mas como dimensão de liberdade, já que agora o mundo físico é submetido pelo animal pela via da capacidade de movimento e pela percepção de distância. Somada à dimensão temporal possibilitada pelo desenvolvimento da capacidade emotiva, essas 
características garantem a transcendência do animal de uma forma evolutivamente superior àquela produzida pelo vegetal.

A soma de movimento e emoção aparece, assim, na teoria de Jonas, como um ponto central de sua compreensão do fenômeno da vida. Sua análise parte da idéia de que o movimento do animal se manifesta em forma de perseguição e fuga e por elas o animal, em busca de sua presa, por exemplo, revelaria não só capacidades motoras, mas também forças sentimentais, ou seja, uma intenção emocional. É o nascimento da capacidade para longos trajetos que efetiva a realidade emocional do animal, porque é o desejo que se esconde por trás da perseguição e o medo por trás da fuga. Como sentimentos, desejo e medo revelam a distância entre animal e planta, já que no primeiro o trajeto entre o instinto e a sua satisfação se efetiva como meta de longo prazo e de longa distância. Para isso, afirma Jonas, é preciso que haja, de antemão, uma percepção da distância e o desenvolvimento dos sentidos, de forma interconectada. É o desejo não realizado que possibilita a meta e mantém o esforço, tornando possível a sua satisfação. Por isso, afirma o autor que "o desejo representa o aspecto temporal da mesma situação cujo aspecto espacial está representado pela percepção” (JONAS, 1998, p. 33), porque a percepção mostra o objeto como "não aqui, mas ali” e o desejo como "ainda não, mas possível".

É essa capacidade que marca o lugar evolutivamente superior do animal em relação ao vegetal: ele pode tornar o "ali” um "aqui” e o "ainda não" um "agora" e isso só é possível pela capacidade do movimento marcado pelo desejo e pela percepção. É esse o grande segredo que impulsiona a vida animal: a capacidade de "manter aberta a brecha entre necessidade imediata e satisfação mediada” (JONAS, 1998, p. 33) e é ela que possibilita pensar em sujeito e objeto, como separação impulsionada pela distância, nos termos descritos até aqui. É só pela separação entre o mundo físico e o organismo que surgem o medo e o desejo e nessa bifurcação reside a condição da existência animal.

Ao contrário do que ocorre no momento primeiro da evolução da vida, quando organismo e seu entorno se relacionam pela via de um metabolismo que se realiza em processos químicos diretos, a criação da distância (e, portanto, do desejo e do medo) - em outras palavras, o surgimento da diferença entre capacidade e necessidade, no qual o organismo e o meio não mais se relacionam apenas como satisfação imediata, mas também como distância e falta - é que acelerou o processo de evolução da vida. Se a planta pode retirar diretamente do solo o seu alimento, no caso do animal essa 
extração se torna muito mais complexa na medida em que depende de corpos orgânicos "altamente específicos". É essa capacidade da planta que a "impediu" de desenvolver aquilo que no animal, por uma necessidade vital, se tornou as novas capacidades nascidas de sua própria precariedade frente à existência. Por desenvolver essas capacidades é que o animal realiza sua liberdade de uma forma superior àquela existente no caso vegetal.

Mas esse é também o seu maior risco, porque em sua complexidade, a vida se manifesta mais dependente dos fatores externos e das capacidades individuais. No meio, o animal exerce tanto a sua liberdade quanto o seu risco. Quanto mais cresce a sua liberdade, mais aumenta o seu risco. Essa é, ao mesmo tempo, a sua grandeza e a sua fragilidade. $\mathrm{O}$ mundo no qual o ser vivo animal se encontra pode ser tão ameaçador quando acolhedor, dependendo da capacidade que ele tem de obter êxito nele. $\mathrm{O}$ mundo contém, nas palavras de Jonas, tanto as coisas que despertam o seu desejo e motivam a sua perseguição, quanto aquelas que despertam medo e provocam a sua fuga. Nesse jogo de distâncias reside seu êxito ou seu fracasso enquanto indivíduo vivo e, consequentemente, enquanto espécie. É como existência passional, portanto, que o animal se projeta na existência, em meios a frustrações, prazeres, sofrimentos, sucessos, deficiências, satisfação etc. É isso que faz dessa tese jonasiana uma "teoria geral da vida", como ele mesmo expressa (JONAS, 1998, p. 32).

Nota-se que essa tese caminha para a afirmação de que é o risco de seu desaparecimento que torna a vida mais interessante e complexa, pois não é pela necessidade de mera conservação que ela se efetiva e evolui, mas, sobretudo pela aventura que ela empreende no misterioso reino da mortalidade. É a possibilidade da morte que torna a vida mais rica, por ser sua característica formadora. É a precariedade da vida e o fato de ser enormemente perecível que faz emergir a percepção, o movimento e o sentimento como suas qualidades - e não apenas como seus meios. Ou seja, essas três capacidades vitais se articulam como marca da própria vida e não apenas como meio para sua conservação.

\section{0 lugar do ser humano na evolução da vida: a existência transanimal do homem}

Como animal, o homem participa dessa aventura e nela ocupa um lugar privilegiado, pelas imensas fragilidades que carrega e que, também nele, 
somam-se ao desenvolvimento de grandes capacidades em busca do êxito existencial. Mas ele é, também, portador de uma existência própria que, nas palavras de Hans Jonas, é sua existência “transanimal” (JONAS, 1998, p. 39) e é ela - independente de que tipo de especificidade se lhe impõe - que o funda como animal vinculado ao mundo de uma forma distinta, como cidadão do mundo, como ser que se sobressai à natureza, como uma sua parte supranatural. O conceito de transanimalidade, assim, autoriza uma perspectiva de análise sob a qual o homem se vê como animal entre os animais e ao mesmo tempo distinto deles. Seu trans é seu trânsito, a um tempo seu movimento, seu atravessamento, seu pertencimento e sua ruptura. Um através que é um para-trás mas também um para-além. Algo que evoca uma transnatureza, evocada também como supranatureza, já que essa supranatureza do humano se efetiva pela sua maior capacidade de obter êxito na luta da vida.

Mas essa supranatureza não autoriza as interpretações que abriram um abismo entre o humano e o animal e ainda mais, entre o humano e a natureza. As conseqüências filosóficas do darwinismo analisadas por Jonas evocam a análise das "vantagens e desvantagens do dualismo para a ciência natural” (2004, p. 64), buscando uma explicação a respeito da acomodação da ciência moderna no pólo da matéria - oposto ao espiritual. Em referência à teoria cartesiana, Jonas demonstra que essa era uma exigência do modelo matemático usado como método da ciência na modernidade: fora preciso destituir a res extensa de tudo aquilo que não poderia ser apropriado pelos "caracteres ontológicos não matemáticos". Tratou-se de eliminar da realidade física as suas "características indesejadas". O dualismo de Descartes reservava, ainda, ao sujeito pensante a condição de um atributo essencial e próprio (a consciência) que o distinguia da realidade física e que possibilitava em ambas as extensões permanecessem radicalmente separadas umas das outras, num processo de separação ontológica de imenso sucesso para a ciência da época. Essa separação levara, entretanto, ao completo abandono do complemente espiritual, como um acabamento absurdo desse dualismo cartesiano. O dualismo leva novamente ao monismo, portanto, opção de toda a ciência natural desde então, que excluía dos organismos vivos algo para além da matéria (a única exceção seria, no caso cartesiano, o próprio homem), já que os animais não passariam de autômatos marcados unicamente pelas leis da matéria e destituídos de qualquer interioridade espiritual. É o homem, como exceção, que coloca nos animais, erroneamente, aquilo que ele sente em si 
mesmo, como uma analogia de si mesmo. Os animais para Descartes seriam apenas corpo ( $c f$. Discurso do método, $\mathrm{V}$ e Tratado sobre o homem) e o organismo, destituído de qualquer premissa espiritual, estaria aberto às pesquisas da ciência natural monista não mais obrigada a se ocupar com os fenômenos do espírito. O mundo estaria, enfim, purificado do espírito - é a que se chegou pelas mãos dos cartesianos (talvez mais do que pelas mãos do próprio Descartes). Nesse modelo, o homem não seria mais do que um "usuário da criação viva" (p. 70), pela via da pretensão antropocêntrica que marca a era moderna e que teria levado à afirmação de que a vida não precisaria de "alma" para se efetivar.

Foi com o evolucionismo, enquanto teoria resultante desse movimento inaugurado pelo cartesianismo, que se chegou à destituição do humano do lugar especial ocupado por ele no reino da vida e que lhe dava possibilidade de avançar sobre todos os demais âmbitos do extra-humano. Pela explicação que recorre ao dinamismo das mutações (necessidade e contingência), o espírito passa a ser entendido como resultado também desse processo dinâmico. Com isso o evolucionismo "minou a construção de Descartes com mais eficiência do que qualquer crítica metafísica seria capaz de fazê-lo" (2004, p. 67) pelo simples fato de ter mostrado a ingenuidade de sua estrutura. Se a derivação animal do homem negava certa pretensa dignidade metafísica do mesmo, deixou-se de ver, afirma Jonas, que esse processo também devolveu ao "reino universal da vida um pouco de sua dignidade" (2004, p. 67), pela via do parentesco entre homens e animais cujas interioridades estão presentes em graus diferentes (no caso humano, inegavelmente, com mais avanços). É assim que, segundo Jonas, o "reino da alma" (com seus "atributos do sentir, tender, sofrer e gozar") era reintegrado, "a partir do ser humano, a todo o reino da vida" (2004, p. 68). O âmbito do espiritual passaria a ser um componente da vida como um todo: "um complemento lógico à genealogia científica da vida” (2004, p. 68).

Nota-se assim, como Hans Jonas pretende retirar da teoria evolucionista as bases para um pensamento que supere o materialismo monista e ao mesmo tempo o dualismo que percorreu toda a ciência moderna. Ele quer introduzir pela porta da frente dessa teoria, uma consequência lógica pouco reconhecida: que ela possibilita pensar a vida como matéria e como espírito, ao mesmo tempo. A pergunta perspicaz é formulada da seguinte maneira: "onde poderá ser colocado o início da interioridade a não ser no início da vida?” (2004, p. 68). Como algo co-extensivo à própria vida, o espírito evoca 
a necessidade de que a ciência reveja os seus pressupostos mecanicistas, já que eles não são mais suficientes para a sua compreensão. É dessa forma que a vitória grandiosa do materialismo, "por sua própria lógica interna" introduziu em seu âmago a semente de sua crise: a evolução, assim compreendida, rompe com os limites antes impostos pelo materialismo e conduz a ciência, sob aspectos filosóficos, à necessidade de reformulação dos seus pressupostos.

O darwinismo, como principal corrente da doutrina evolucionista, teria como consequência dialética o alargamento das fronteiras ontológicas para além do campo materialista. De suas conseqüências, poder-se-ia retirar, afirma Jonas, possibilidades de correções do abismo que se ergueu entre o homem e a natureza, abismo esse aberto tanto pelo dogma judaico da Criação, quanto pela metafísica racional grega e pelo trascendentalismo cristão (JONAS, 1998, p. 41). Assim, o darwinismo não poderia ter outro efeito: um schock contra a unilateralidade interpretativa que vingou no ocidente na maior parte de sua história. Reconhecendo a legitimidade das reações provocadas pela tese darwinista, Jonas também chama a atenção, pelo que se viu acima, para o fato de que a sua verdade também esconde outras possibilidades de interpretação.

Assim, caberia à antropologia filosófica recolher as conseqüências da interpretação do humano através do conceito de transanimalidade do homem: "Para encontrar a justa medida entre as unilateralidades, chegou o tempo para a tarefa da antropologia filosófica de voltar a refletir sobre o essencialmente transanimal no ser humano, mas sem negar a sua animalidade” (JONAS, 1998, p. 41). Assim, o darwinismo evoca uma compreensão do homem que passa a exigir um olhar que redescubra o homem como um desenvolvimento superior dentro da existência animal e é só como tal que a ele pode ser efetivada a noção de responsabilidade. É como parte do processo de evolução da vida que o homem, por se sobrepor ao caráter imediato dos demais seres e pela capacidade que ele mantém de autocompreensão, que ele se torna o agente da responsabilidade.

\section{Técnica, arte e metafísica:}

\section{do homo faberao homo pictore dele ao homo sapiens}

A análise de Jonas na primeira parte da compilação de textos escritos na década de 1990 e reunidos na obra Philosophishe Untersuchungen und 
metaphysische Vermutungen, tenta demonstrar ainda a novidade trazida pelo homem no que tange ao seu lugar no desenvolvimento da vida e ela é realizada a partir da apreciação de algumas características próprias ao indivíduo humano, três para ser exato: a ferramenta, a imagem e a tumba (JONAS, 1998, p. 424). Essas três características teriam sido escolhidas pelo autor por remeterem a testemunhos concretos aparecidos antes das culturas históricas e que possibilitam um olhar menos duvidoso sobre a origem humana capazes de distinguir o homem dos demais seres vivos e que dariam alguma coordenada para a sua análise filosófico-antropológica.

A ferramenta é o primeiro alvo dessa análise. Ela representa algo humano porque diverge mesmo do ser humano, é algo por ele criado sem nenhuma função orgânica. Ao contrário, como algo artificial, toda ferramenta é um retrato da imaginação humana que se revela num elemento material. Nela reside a prova da capacidade imaginativa do homem, portanto. É um retrato, além disso, de sua liberdade imaginativa e criativa. Por estar ligada a um caráter utilitário, obviamente que a ferramenta também demonstra as "transições difusas entre realizações animais e humanas" (JONAS, 1998, p. 44). Isso, obviamente, não ocorre com a produção de imagens, já que, nesse caso, há uma nítida diferenciação entre o animal e o humano, algo estritamente não gradual, mas marcado por uma ruptura. A assertiva de Hans Jonas é fecunda: "Partindo da evidência intuitiva, o homo pictor, o produtor de imagens, nos ensina que o homo faber, o mero produtor e usuário de ferramentas, por si mesmo ainda não é plenamente o homo sapiens" (JONAS, 1998, p. 44).

As conseqüências dessa afirmação serão retomadas n'O princípio responsabilidade do ponto de vista ético, como denúncia do seqüestro do homo sapiens por parte do homo faber no que tange à descrição jonasiana do poder representado pela técnica moderna como domínio sobre a natureza: "Assim, o triunfo do homo faber sobre o seu objeto externo significa, ao mesmo tempo, o seu triunfo na constituição interna do homo sapiens, do qual ele outrora costumava ser uma parte servil” (JONAS, 2006, p. 43). Em outras palavras, pela via da técnica moderna e do esquecimento de seu poder,

\footnotetext{
${ }^{4}$ Muitas das ideias presentes nesse texto, intitulado "Ferramenta, imagem e túmulo: o transanimal no ser humano" encontram-se também no capitulo "Homo pictor. a liberdade da imagem", d'O Princípio Vida (p. 181s).
} 
o homem retornou sua ancestralidade em sentido negativo, quando ainda não era capaz a não ser de fabricar ferramentas. Essa constatação é evidente:

A nossa [cultura] põe na atualidade maior ênfase no que se anuncia na ferramenta: a técnica e a ciência natural que está a seu serviço. $\mathrm{O}$ que se achava mais próximo à finalidade biológica e sua dinâmica de seleção, o que apareceu primeiro como tributo à dependência da natureza e que se opunha a esta como ajuda, isto é o que hoje se sobressai com seus nunca suspeitados êxitos que se vão superando sempre de novo e que dominam toda a nossa existência, destacando entre tudo o mais que nos distingue "de todos os seres que conhecemos" (JONAS, 1998, p. 55)

A questão biológica, assim, se articula como problema ético, na medida em que o ser humano moderno rende-se à redução de suas capacidades inventivas e celebrativas, reduzindo sua transanimalidade ao horizonte diminuído da técnica, em tempos, como o nosso em que tanto a arte quanto a metafísica - escreve em aparente tom de lamento o autor estão em descrédito.

A arte dos desenhos em pedra, ao contrário, representa a prova cabal de que só o homem poderia realizá-los simplesmente pelo fato de que sejam biologicamente inúteis. Enquanto os artefatos e ferramentas tem algum uso prático e portanto, ainda conectam o homem ao animal, a representação pictórica não realiza senão uma vocação de outros fins que não os biológicos. Esta é sua novidade.

Como representação, toda pintura não é uma repetição, mas um símbolo, uma insinuação, uma reprodução da aparência que permite uma "economia da omissão e da simplificação, mas também da exageração, deformação e estilização” (JONAS, 1998, p. 45), ou seja, trata-se de um sinal a ser interpretado e para cuja interpretação só o humano tem as capacidades. Nela cabem generalizações, abreviaturas e jogo de aparências que mostram como a imagem está desprendida do objeto que ela representa. Sua "leitura" implica a capacidade de uma recordação que ultrapassa a mera memória animal e aproxima-se da suposição e, logo, da criação. O homem é tal porque cria. Essa é a uma manifestação da plenitude de sua liberdade e trata-se de um "feito transanimal exclusivamente humano" (JONAS, 1998, p. 49) pelo qual 
o movimento muscular não é regido mais por esquemas fixos, mas pela capacidade imaginativa e intencional. O homo pictor é o que faz projetos interiores e os exterioza em forma artística. E, assinala Jonas, essa capacidade está intimamente ligada à produção da linguagem, já que dar nomes é uma forma de criação de ordem: desenhar uma imagem é similar, afirma o filósofo, à capacidade de nomear uma imagem. Homo pictor e homo sapiens então se encontram.

Esse mesmo esquema Hans Jonas encontra no túmulo: a tumba é também uma expressão de transanimalidade do homem, pois também serve de comunicação, instrução e invenção. "O fato empírico de que nenhum animal enterra seus mortos ou segue prestando-lhes atenção nos diz que o túmulo é exclusivamente humano" (JONAS, 1998, p. 51). A memória e o culto aos mortos evoca algo novo porque está ligado às crenças, que é a forma pela qual o humano projeta-se para fora de sua finitude, do que é visível e sensível. Como o único animal que sabe que vai morrer, o homem é o único que está capacitado para pensar sobre si mesmo: a pergunta sobre o além remete, imediatamente, à pergunta sobre o agora e o aqui. É ela que dá origem à reflexão. E é ela a característica fundamental que o homem descobre em si mesmo. Por isso, afirma Jonas, "dos túmulos se levanta a metafísica" (JONAS, 1998, p. 51) - nome aliás, de uma certa maneira, da primeira filosofia. O que ele descobre em si não é, entretanto, uma resposta, mas vacilações interpretativas que se revelam, entre outras coisas, na necessidade de manter os vínculos com os antepassados.

A capacidade reflexiva é apontada por Jonas como "o cúmulo do princípio de mediação com o qual a vida começou e cujo aumento se pode seguir através de toda evolução orgânica” (JONAS, 1998, p. 52). O homem aparece quando ele, depois de pintar um animal numa caverna e mesmo o seu caçador, torna-se capaz de diferenciar-se dessa imagem para criar uma imagem sobre si mesmo, através do processo reflexivo. Só assim, passamos do homo pictor para o homo sapiens. Por meio desse distanciamento ele se constitui como um "eu” no mundo. É aí, também, que se efetivam seus maiores perigos, muitas vezes revelados em forma de desespero radical, cujo resultado pode ser o suicídio. A causa, diz Jonas, pode ser que o homem tenha se tornado uma pergunta para si mesmo - é esse seu perigo: "Quaestio mihi factus sum" (JONAS, 1998, p. 53). Da ferramenta nasce a técnica; da imagem nasce a arte; do túmulo nasce a metafísica: o processo revela o 
quanto Jonas entende a trajetória da vida como um processo contínuo de ampliação das capacidades e possibilidades.

\section{Considerações finais}

Nessa tríplice perspectiva, o animal-homem encontra sua transanimalidade, ou seja, por elas ele consegue dar uma resposta humana (propriamente falando) para a condição partilhada com os demais animais. Pela ferramenta, pela imagem e pelo túmulo, o homem sustenta uma relação transanimal com o mundo e sobre eles funda sua diferenciação. $\mathrm{O}$ conceito de transanimalidade, assim, evoca a perspectiva de religamento do homem no processo evolutivo da vida e ao mesmo tempo não prescinde de sua característica própria, pela qual ele, em nome da grande liberdade que usufrui, tem também o maior dos riscos (o de destruição de sua própria vida e da vida dos demais seres), fato que lhe impõe a maior das responsabilidades.

Por meio dessas três características inerentes à condição humana (e que, a um tempo, ligam o homem ao animal e o diferenciam dele) é que o homem toma consciência de si e, consequentemente, dos demais seres e das suas ações sobre eles. É no eu-reflexivo de si que Jonas funda o princípio da responsabilidade do humano. Em outras palavras, da liberdade natural nasce a liberdade reflexiva e ela remete à liberdade moral "prefigurada nas anteriores” (DIÁZ, 2007, p. 92). É por possibilitar a liberdade de escolher e de eleger princípios, que a reflexão conduz à moral e pela qual o homem se opõe ao mundo natural e aos seus imperativos, pela via da escolha. Entretanto, essa liberdade vem, como já vimos, acompanhada de maiores riscos e de um mais forte sentimento de precariedade do homem frente à natureza.

Como ápice, o homem dá ao processo evolutivo um caráter eminentemente ético, porque nele reside a capacidade de dar continuidade à vida ou não. É essa capacidade livre de decisão que dá ensejo à ética jonasiana, no qual a natureza aparece como o lugar no qual o homem julga a sua responsabilidade. 


\section{Referências}

DIÁZ, P. A. El principio de responsabilidad: del optimismo científico-técnico a la prudência responsable. Tese de doutorado. Granada: 2007. 386 p.

JONAS, H. O fardo e a bênção da mortalidade. Trad. Wendell Evangelista Soares Lopes In: Princípios. Natal, v. 6, n. 25, jan./jun. 2009, p. 265-281.

. "Evolution et Liberté". In Evolution et Liberté. Traduit de l'allemand et présenté par Sabine Cornille et Philippe Ivernel. Paris: Payot \& Rivages, 2005, p. 2557.

. Memórias. Trad. Illiana Giner Comín. Madrid: Losada; Oviedo, 2005.

Pensar sobre Dios y otros ensayos. Trad. Angela Ackermann. Barcelona: Herder, 1998.

O princípio responsabilidade. ensaio de uma ética para a civilização tecnológica. Trad. Marijane Lisboa, Luiz Barros Montez. Rio de Janeiro: Contraponto : Ed. PUCRio, 2006.

O princípio vida: fundamentos para uma biologia filosófica. Trad. Carlos Almeida Pereira. Petrópolis: Vozes, 2004.

E-mail: jelsono@yahoo.com.br

Recebido em: Setembro/2010

Aprovado em: Outubro/2010 